\title{
Predicting the Rise of EU Right-Wing Populism in Response to Unbalanced Immigration
}

\author{
Boris Podobnik, ${ }^{1,2,3,4,5}$ Marko Jusup, ${ }^{6}$ Dejan Kovac, ${ }^{7,8,9}$ and H. E. Stanley ${ }^{1}$ \\ ${ }^{1}$ Boston University, Boston, MA 02215, USA \\ ${ }^{2}$ Faculty of Information Studies, SI-8000 Novo Mesto, Slovenia \\ ${ }^{3}$ University of Rijeka, 51000 Rijeka, Croatia \\ ${ }^{4}$ Zagreb School of Economics and Management, 10000 Zagreb, Croatia \\ ${ }^{5}$ Luxembourg School of Business, 2453 Luxembourg, Luxembourg \\ ${ }^{6}$ Center of Mathematics for Social Creativity, Hokkaido University, Sapporo 060-0812, Japan \\ ${ }^{7}$ CERGE-EI, Praha 1, 11000 Nové Město, Czech Republic \\ ${ }^{8}$ Woodrow Wilson School of Public and International Affairs, Princeton University, Princeton, NJ 08544, USA \\ ${ }^{9}$ Adriatic Economic Association, 10000 Zagreb, Croatia \\ Correspondence should be addressed to Boris Podobnik; bp@phy.hr
}

Received 19 February 2017; Revised 15 May 2017; Accepted 15 June 2017; Published 7 August 2017

Academic Editor: Fabio Caccioli

Copyright (C) 2017 Boris Podobnik et al. This is an open access article distributed under the Creative Commons Attribution License, which permits unrestricted use, distribution, and reproduction in any medium, provided the original work is properly cited.

\begin{abstract}
Among the central tenets of globalization is the free migration of labor. Although much has been written about the benefits of globalization, little is known about its limitations and how antiglobalist sentiment can be strongly affected by high levels of immigration. Analyzing poll data from a group of EU countries affected by the recent migrant crisis, we find that over the last three years the percentage of right-wing (RW) populist voters in a given country depends on the prevalence of immigrants in this country's population and the total immigration inflow into the entire EU. The latter is likely due to the perception that the EU functions as a supranational state in which a lack of inner borders means that "someone else's problem" can easily become "my problem." We find that the increase in the percentage of RW voters substantially surpasses the percentage of immigration inflow, implying that if this process continues, ongoing democratic processes will cause RW populism to prevail and globalization to rapidly decrease. We locate tipping points between the fraction of immigrants and the rise of RW populism, and we model our empirical findings using a complex network framework in which the success of globalization rests on a balance between immigration and immigrant integration.
\end{abstract}

\section{Introduction}

An important goal of globalization is to allow both capital and labor to move freely across national borders [1-4]. Although one EU country that lacks a sufficient labor force can draw from another EU country that has an overabundance of labor, this economic consideration neglects how movement of people can affect public opinion and alter the outcome of subsequent elections. A volatile situation can arise when either the native majority or the migrant minority sense that their national, ethnic, or religious identity is being threatened. Thus the unprecedented inflow of immigrants into the EU during the recent migrant crisis allows fresh insights into the relationship between immigration and the popular vote and-by extension - the factors that directly affect the success of further globalization.

Although a large body of literature is dedicated to the analysis of how migration affects the global economy [1$3,5-10]$ and right-wing (RW) populism [11-17], much less is known about the limitations of globalization $[4,18]$, especially how large-scale migrations sway the popular vote and what the economic consequences may be. For example, analyzing national elections in 16 European countries from 1981 to 1998 Swank and Betz reported that the welfare state directly depresses RW populism [9]. Smith reported that RW populist parties benefit from higher levels of crime by linking crime 
with higher levels of immigration [16]. Borjas reported that the integration of immigrants into the US was slow and that it took four generations for the earnings of immigrants to equal the earnings of natives, not one or two as commonly believed [19].

Although the recent migrant crisis in the EU was caused by political turmoil and armed confrontation, not globalization, some of the central tenets of globalization have nevertheless been tested. The surge in the population of immigrants has been matched by a surge in voters supporting RW populist parties. The growing number of RW voters across the EU suggests that tolerance towards immigrants is conditional [20] and that members of the general public previously not identifying with RW populism have become supporters. If globalization is to succeed, we must understand this "change of heart." When immigration is more rapid than integration over a prolonged period of time [20], RW populist movements can win elections and this can cause globalization to decline. Apart from concerns about globalization, expected global climate change strongly indicates possible massive displacements in the global population [21].

Why immigration in the past decades did not stir as much RW populism across the EU as the most recent inflow did is perhaps because the EU societies are approaching a tipping point characterized by drastic political and economic upheaval. The term tipping point is used (i) to denote a possible change during which RW populism becomes the ruling political option and (ii) to emphasize a potentially sudden (nonlinear) aspect of such a change that may not even be visible in the available data. It may not be globalization and immigration themselves that are the root of the problem, but rather the high speed at which these processes are occurring right now. Herein, we find that during the last three years the rise of RW populism in a set of EU countries has been substantially more rapid than the immigrant inflow into the EU. We report that the percentage of RW voters in a country significantly depends on the percentage of immigrants within this country and the total immigration inflow into the entire EU. We also find that the occurrence of violent incidents is unrelated to the rate of immigrant inflow and has little effect on the rising percentage of RW voters. We identify tipping points connecting the percentage of immigrants and the popularity of RW populist parties. Globalization is meant to be a tolerant form of democracy in which cooperation between nations supersedes individual national interests, but there are circumstances under which growing RW populist movements can overthrow this tolerant form of democracy. We analyze whether the interconnectedness between countries characteristic of globalization can facilitate cascades (i.e., domino effects) in which growing populist movements within one country trigger similar movements in other countries.

\section{Results}

It seems reasonable that the causes of populist behavior are, at least partly, nation-dependent. Generally, when a society is relatively far from a tipping point, the nation's interests likely span a multidimensional space. For example, according to
Eurobarometer 65 published in 2006, the main concerns of European citizens were unemployment (49\%), crime (24\%), economic health (23\%), immigration (14\%), and terrorism (10\%). In a concurrent survey in the UK, however, $38 \%$ of the respondents listed race and immigration as the top issue. Because RW populism in the UK eventually led to a win over the BREXIT vote, previous surveys suggest an intriguing possibility that, as a society approaches a tipping point, its multidimensional space starts to shrink, finally reducing to a one-dimensional space in which a single issue dominates the current affairs. Inspired by the developments in the UK, we analyze the rise of RW populism in the EU, wherein the recent migrant crisis suggests that the Union is approaching a tipping point.

RW populism often embraces intolerance, which is a widespread social phenomenon that produces conflicts and generates segregation [22-28]. Intolerance combined with radicalization is the main cause of violence and terrorism [29-33]. However, RW populism often shares certain values, for example, antiglobalization, protectionism, and Euroscepticism, with left wing (LW) populism. In principle, people not satisfied by the current government can swing between RW and LW populism. Such a cyclic dynamics may arise as the prevailing issues (e.g., economic versus ethnic) change at a faster-than-generational time scale. Here we focus only on RW populism and the fraction of RW populist voters in response to unbalanced immigration as the driving factor.

For each country affected by the recent migrant crisis, we calculate the percentage of immigrants from September 2013 to September 2016 by combining the official value for 2013 with the number of visa applicants recorded monthly $[34,35]$. We then collect the available election poll data and election results for the same range of months [36]. Figure 1(a) shows that in June 2016 in this set of EU countries there is a rising trend in the percentage of RW populist supporters in response to the increasing percentage of immigrants in the general population. We calculated the best linear fit that can be interpreted as the cumulative probability function of a uniform distribution. From this fit we estimate that when the fraction of immigrants reaches approximately $30 \%$, RW populism attains the majority. The slope value of 1.80 is highly statistically significant ( $t$-statistic $=2.62$ ). Besides the linear fit, we relate the fractions of immigrants and RW votes using the cumulative exponential probability function, thus finding that as the percentage of immigrants approaches approximately $22 \%$, the percentage of RW populist voters exceeds 50\%, which is again the threshold at which in democratic societies a party can take over the government. The considerable scattering of the data suggests that tolerance levels may differ among countries, and the lower the percentage of immigrants needed to trigger high levels of RW populism in a country, the lower the level of tolerance in that country. Figure 1(b) shows, for example, that in Austria the 50\% threshold is reached even when the percentage of immigrants is below $20 \%$.

The current fraction of immigrants in the general population is not the only factor that affects voter sentiment. Figure 2 uses the data for Austria and Germany for 2013-2016 and shows that the growing percentage of RW populist supporters 


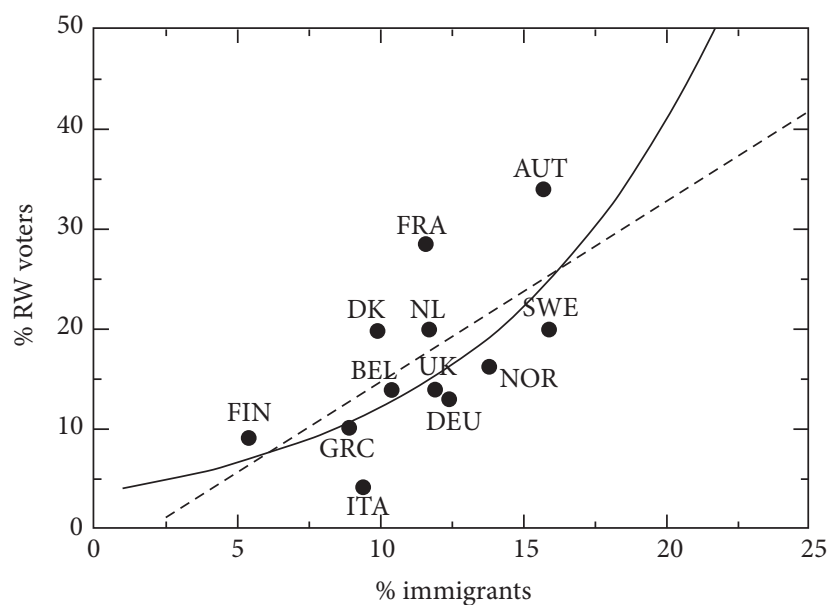

(a)

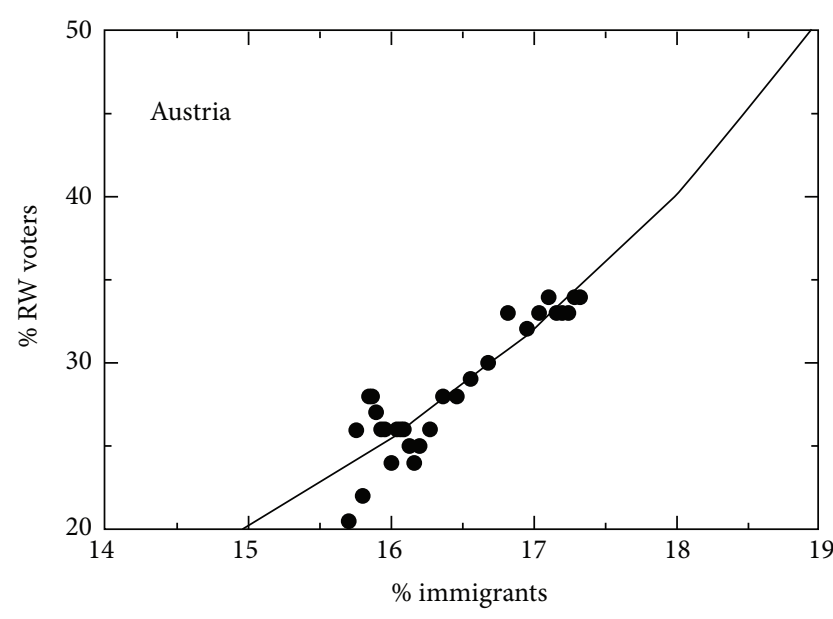

(b)

FIGURE 1: Immigration affects the support for right-wing populism I. (a) Among the EU countries involved in the recent migrant crisis, support for RW populism is generally higher in those countries that accepted a larger number of immigrants relative to the country's population size. Shown is June 2016. Seeing democracy as the majority rule principle, we presume that RW populism becomes a dominant political option when the percentage of RW voters exceeds $50 \%$. Judging based on a cumulative exponential function that fits the data reasonably well $-y=4.43 \exp (0.097 x)-\mathrm{RW}$ populism in the examined EU countries may take over if the percentage of immigrants in the total population approaches $22 \%$. Shown is also a linear fit $y=-3.67+1.80 x$ roughly giving that the RW populism reaches the majority for the percentage of immigrants equal to approximately $30 \%$. Coefficients of determination $\left(R^{2}\right)$ for the two models are 0.3866 and 0.4077 , respectively. Akaike weights indicate that, given the dataset at hand, the exponential model is better with probability $44.3 \%$, while the linear model is better with the remaining probability $55.7 \%$. (b) Similar as in the other EU countries, Austrian data reveal that the increase in the percentage of immigrants is accompanied with an increase in the percentage of RW populist voters. Here too a cumulative exponential function fits the data well. This function predicts the rise of RW populism in Austria when the percentage of immigrants is slightly below the $20 \%$ mark.

is responding to the inflow of immigrants. For example, in Austria the far-right party won $20.5 \%$ of the popular vote in 2013 in response to the percentage of immigrants living in Austria at the time, but in the second half of 2015 the inflow of immigrants increased sharply $[34,35]$ and a local election in Vienna saw the percentage of RW votes jump to $33 \%$. This sudden change suggests the presence of a phase transition, tipping point, or critical point $[37,38]$; that is, the nearer the percentage of immigrants comes to the tipping point, the more quickly voters turn to extreme political alternatives. Figures 2(b) and 2(c) show a qualitatively similar phenomenon occurring in Germany.

In an attempt to probe deeper into the internal dynamics of RW populism in the EU as a function of the inflow of immigrants, next we analyze how the immigration rate affects the rise in RW populist voters. In Figure 3, we qualitatively represent the annualized increase in RW votes by taking the differences between the popularity of RW populist parties in September 2016 and September 2013 and subsequently annualizing these differences by dividing them with the number of years in the specified period. Surprisingly, for a group of countries in which the annualized increase in the percentage of RW voters exceeded 2\%, Figure 3 shows that this increase is practically independent of the inflow of immigrants. Why would countries with a relatively high and a relatively low inflow of immigrants exhibit about the same increase in the percentage of RW voters? This result may be a consequence of the EU's political organization. Because the EU functions practically as a supranational state with no internal borders, if one country decides to accept immigrants, this decision may have repercussions for all the other member states. The increase in the percentage of RW populist voters may therefore more systematically depend on the total inflow of immigrants into the entire EU, expressed here as a percentage of the total EU population, than the inflow in any individual country.

Anecdotal evidence to this effect can be seen in the case of Sweden and Norway. Sweden was among the countries hit hard by the recent migrant crisis, yet Norway had approximately the same annualized increase in the percentage of RW voters. A similar occurrence happened in Germany and Poland. Germany experienced a high inflow of immigrants, and in Poland 53\% of the population wanted their government to refuse asylum seekers from the Middle East and North Africa, and only 33\% thought the opposite. If Poland has already transitioned from the tolerant mode of democracy associated with globalization to a mode dominated by RW populism, then the fraction of immigrants at which the Polish population is pushed beyond the tipping point is much lower than in western EU countries. Poland and Hungary both share decades of socialist experience and are both among the toughest opponents of immigration into the EU. Both strongly oppose EU quotas designed to evenly spread the shock of the migrant crisis. 

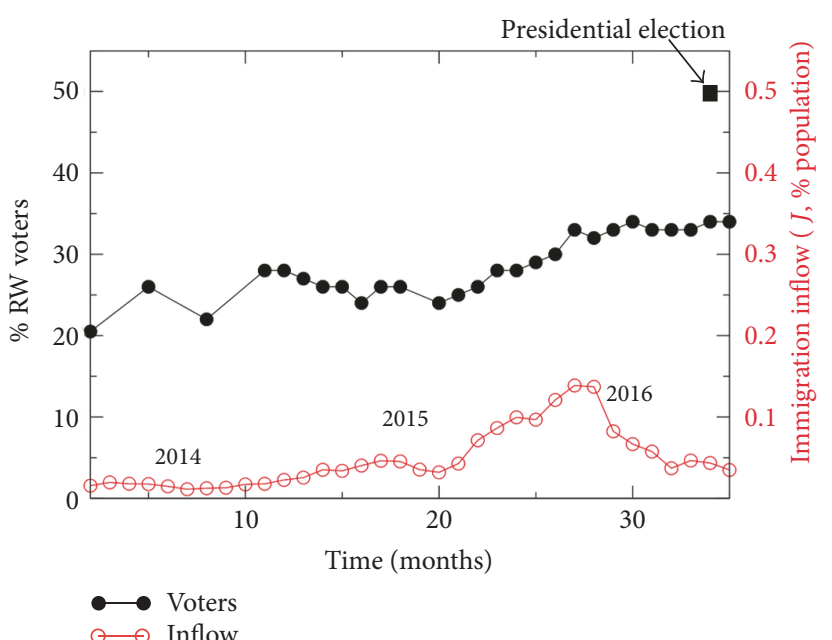

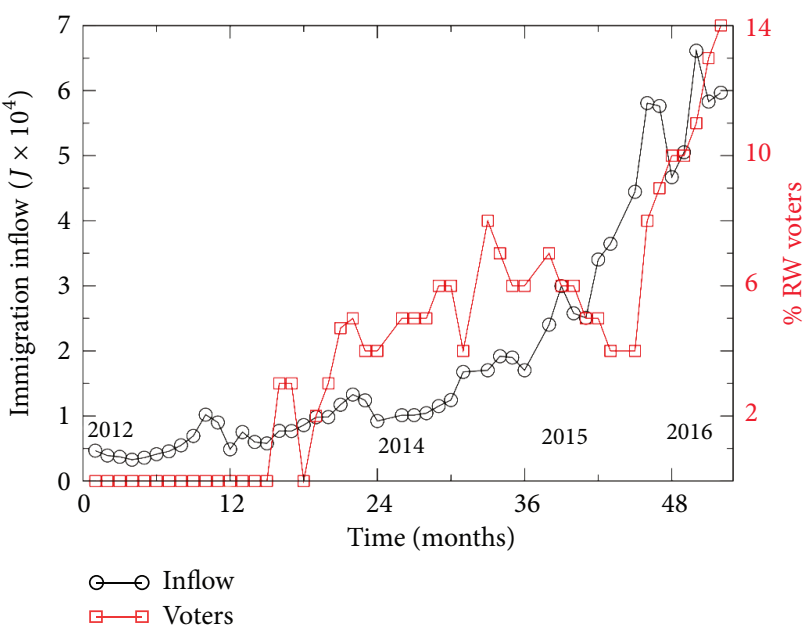

(b)

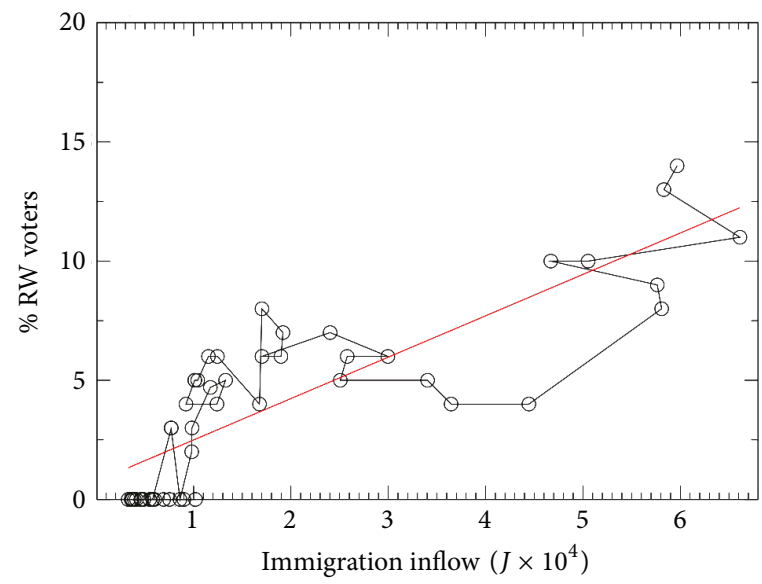

(c)

FIGURE 2: Immigration affects the support for right-wing populism II. (a) An unprecedented inflow of immigrants into Austria coincided with a steady increase in the fraction of RW populist voters. A solitary black dot represents the results of Austrian presidential election in May 2016 in which an RW populist candidate secured almost 50\% of votes. This election shows that even after the record immigrant inflow at the end of 2015 had subsided, a decreasing trend in the number of immigrants that enter Austria did not automatically translate into lower support for the RW populist political option, that is, RW populism seems to be more than just a craze. (b) In Germany, the increasing inflow of immigrants (monthly data $[34,35]$ ) rather clearly coincided with the increasing support for an RW populist party. (c) A significant regression emerges when the German case is presented as a scatter plot between the inflow of immigrants and the percentage of far-right voters.

Figure 3 indicates that the interplay of factors influencing the rising popularity of RW populism is more complex than a simple bivariate regression, and thus we turn to econometric analysis and multivariate regression. Using the results of the simple regression in Figure 1, we assume that the fraction of $\mathrm{RW}$ voters (response variable, $\mathrm{RW}_{t}$ ) in a given country is determined by the fraction of immigrants $\left(\mathrm{IM}_{t}^{L}\right)$ living in the country. We further assume that the fraction of RW voters depends on the overall inflow of immigrants into the $\mathrm{EU}\left(\mathrm{IM}_{t}^{\mathrm{EU}}\right)$ calculated relative to the total EU population. This variable represents an "immigration shock" in the model. To also take into account the possibility that violent incidents involving immigrants could affect the popular vote, we include the total number of injuries $(I)$ and casualties
(D) involving immigrants recorded across the EU [39] in the model. Additionally, we take into account the unemployment rate $(U)$ that might also affect the popular vote. Finally, we add a variable $M_{i t}=(1-$ MIPEX/100) in which MIPEX is the migrant integration policy index [40], a proxy for the integration rate-the larger the MIPEX, the better the integration.

We perform econometric analysis using a pooled timeseries cross-section (TSCS) method that combines the crosssectional data on multiple countries. Here the number of countries is $N=10$, entirely consisting of the so-called old democracies: Germany, France, Austria, Netherlands, Sweden, Norway, Denmark, Finland, Greece, and Italy. Because for each country there are $T$ observations along the temporal dimension, the entire dataset has $N \times T=370$ observations. 


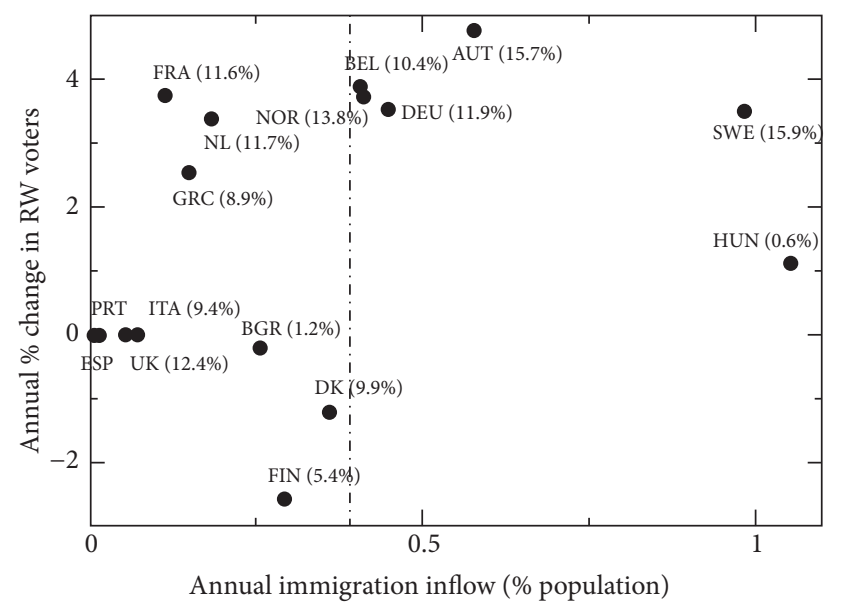

FIGURE 3: Immigrant inflows and the popularity of right-wing populist movements-a nonlinear threshold. Shown is the annualized immigrant inflow into a given country (horizontal axis) as a percentage of that country's population, as well as the corresponding percentage change in RW populist votes (vertical axis). In parentheses are the fractions of immigrants in the total population of the corresponding country. For a group of countries in which the annualized increase in the percentage of RW voters exceeded $2 \%$, this increase is virtually independent of the inflow of immigrants. Such a result may reflect the EU's political organization, that is, the lack of internal borders whereby if one country decides to accept immigrants, the decision may have repercussions for all the other member states. We also observe a threshold indicated by a dashed line at which the immigrant inflow into a given country is sufficiently high to invariably provoke an increase in the percentage of RW populist voters. In the model construction, this threshold suggests $\alpha=0.004$ on an annual basis.

We have an extra index $i=1,2, \ldots, N$ that refers to a crosssectional unit giving

$$
\begin{aligned}
\mathrm{RW}_{i t}= & \beta_{0}+\beta_{\mathrm{IM}}^{L} \mathrm{IM}_{i t}^{L}+\beta_{\mathrm{IM}}^{\mathrm{EU}} \mathrm{IM}_{i t}^{\mathrm{EU}}+\beta_{D}^{\mathrm{ter}} D_{i t}+\beta_{I}^{\mathrm{ter}} I_{i t} \\
& +\beta_{U} U_{i t}+\beta_{M} M_{i t}+e_{i t},
\end{aligned}
$$

where $e_{t}$ is the random error.

Table 1 shows the results of the TSCS regression model, indicating that the fraction of immigrants in the general population and the immigration inflow into the entire EU are the significant explanatory variables. In addition, the coefficient $\beta_{\text {IM }}^{L}$ is not only significant but also higher than unity. Perhaps surprisingly, the response variable is not significantly affected by the number of injuries and casualties in violent incidents involving immigrants. We also show that unemployment insignificantly affects the popular vote.

The aforementioned survey data suggest that not every EU nation is equally tolerant to immigrants. We believe that a proxy for this tolerance can be a fraction of RW votes just after the Second World War $\left(\mathrm{RW}_{0}\right)$ when the fractions of immigrants were considerably smaller than nowadays. Note that by far the largest fraction of RW votes was recorded in Austria, $11.67 \%$. Table 2 show the results of the TSCS regression model when $\mathrm{RW}_{0}$ is included. We find that this
TABLE 1: Pooled time series cross-section (TSCS) analysis with random-effects GLS regression as defined in (1). Test statistics: Wald $\chi^{2}(6)=147.87$ and Prob $>\chi^{2}=0.000$.

\begin{tabular}{lcccc}
\hline & Coeff. & Std. err. & $z$ & $P>|z|$ \\
\hline$\beta_{\mathrm{IM}}^{L}$ & 2.17 & 0.527 & 4.12 & 0.000 \\
$\beta_{\mathrm{IM}}^{\mathrm{EU}}$ & 431.1 & 53.2 & 8.10 & 0.000 \\
$\beta_{\text {ter }}^{D}$ & $-3.7 e-04$ & $4.9 e-04$ & -0.78 & 0.437 \\
$\beta_{\text {ter }}^{I}$ & $2.1 e-04$ & $1.6 e-04$ & 1.28 & 0.202 \\
$\beta_{M}$ & 0.208 & 0.212 & 0.98 & 0.325 \\
$\beta_{U}$ & -0.167 & 0.348 & -0.48 & 0.630 \\
$\beta_{0}$ & -0.298 & 0.103 & -2.89 & 0.004 \\
\hline
\end{tabular}

TABLE 2: Pooled time series cross-section (TSCS) analysis with random-effects GLS regression as defined in (1). Test statistics: Wald $\chi^{2}(6)=151.54$ and Prob $>\chi^{2}=0.000$.

\begin{tabular}{lcccc}
\hline & Coeff. & Std. err. & $z$ & $P>|z|$ \\
\hline$\beta_{\mathrm{IM}}^{L}$ & 1.32 & 0.445 & 2.96 & 0.003 \\
$\beta_{\mathrm{IM}}^{\mathrm{EU}}$ & 455.9 & 53.5 & 8.52 & 0.000 \\
$\beta_{D}^{\text {ter }}$ & $-4.2 e-04$ & $4.9 e-04$ & -0.86 & 0.392 \\
$\beta_{I}^{\text {ter }}$ & $2.2 e-04$ & $1.6 e-04$ & 1.38 & 0.167 \\
$\beta_{M}$ & -0.019 & 0.2 & -0.09 & 0.926 \\
$\beta_{U}$ & -0.015 & 0.289 & -0.05 & 0.959 \\
$\mathrm{RW}_{0}$ & 0.904 & 0.562 & 1.61 & 0.108 \\
$\beta_{0}$ & -0.139 & 0.093 & -1.50 & 0.133 \\
\hline
\end{tabular}

TABLE 3: Pooled time series cross-section (TSCS) analysis with random-effects GLS regression. Test statistics: Wald $\chi^{2}(5)=142.4$ and Prob $>\chi^{2}=0.000$.

\begin{tabular}{lcccc}
\hline & Coeff. & Std. err. & $t$ stat. & $P>t$ \\
\hline$\beta_{\mathrm{IM}}^{L}$ & 2.17 & 0.466 & 4.65 & 0.000 \\
$\beta_{\mathrm{IM}}^{\mathrm{EU}}$ & 467.2 & 50.1 & 9.33 & 0.000 \\
$\beta_{0}$ & -0.235 & 0.056 & -4.15 & 0.000 \\
\hline
\end{tabular}

new regression insignificantly contributes to modern RW populism.

Table 3 shows the results of the TSCS regression model without MIPEX, unemployment, and violent incidents. Interestingly, with the total inflow of immigrants into the EU of 100,000 on a monthly basis, coefficient values in Table 3 suggest that around $30 \%$ of immigrants in the total population of a country are sufficient to cause larger than $50 \%$ support for RW populist parties, which corresponds to the result obtained by a linear fit in Figure 1.

The analyzed data do not indicate whether the rise of RW populism is a transient phenomenon or a longer-term change in political orientation. One factor is the persistence of voter memory. In the October 2015 local election in Vienna the RW populist party won $33 \%$ of the popular vote. During the presidential election a few months later the migrant crisis had reached a peak and the RW populist movement candidate secured almost $50 \%$ of the votes, narrowly losing to a leftist rival. These results have been contested and a new election in December 2016 brought around 48\% to the RW populist candidate, indicating that this rise in RW populism is not 
short-term. This phenomenon has been described in the literature. Betz [41] describes how a substantial increase in the number of refugees and illegal immigrants in European countries during the 1980s provoked a wave of radical RW populism. Following these events in the early 1990s there remained between $11 \%$ and $14 \%$ of Europeans who felt the presence of other nationalities, races, and religions to be unsettling [41].

\section{Model}

Human interactions are often heterogeneous and prone to abrupt nonlinear responses. Because this characterizes the rise of the RW populist party and its RW candidate in the Austrian elections, such linear approaches as the regression in (1) yield only partial results. A useful intuition is gained by thinking about the election system in a democratic country as a random walker. Even in a bipolar political system, not every left government is equally left, and similarly not every right government is equally right. Therefore, as a result of election, the random walker can move either left or right, with the size of this move depending on the standard deviation. Without limitations such that democracy and the election process possess an unlimited tolerance for every political option, after a long enough time the random walker is bound to end up either extremely right or extremely left. Both of these limits exhibit ideological rigidity likely to substantially reduce the level of democracy and tolerance-in agreement with Popper: "unlimited tolerance must lead to the disappearance of tolerance" [42]. Thus, RW populism can be considered as just one of the two random walk limits. However, the random walker intuition does not explain why a society would move left or right nor does it provide a microscopic interpretation of the societal processes at the individual agent level.

To mechanistically characterize the rise of RW populism and account for the existence of tipping points in social dynamics, we use a complex network approach [20, 43-45]. Complex network science is able to emulate heterogeneity in human interactions and goes beyond capturing the dynamics near tipping points. Heterogeneity is important when considering immigration and integration issues, because immigrants in order to sustain their identity live in "hubs" that make them more difficult to integrate than immigrants mixed into the native population.

We construct our model by setting a constant number of native "insider" agents and arranging them in an ErdösRényi random network of business and personal contacts. Immigrant "outsider" agents are then added to the network. Each insider notices the percentage of outsiders in their neighborhood and based on this percentage decides whether to be supportive of globalization or RW populism. Insider agents get information from their neighborhood and the interaction is local, and this data is essential in understanding tipping points [46], but there are also other relevant, nonlocal interactions. There is furthermore the factor that information can be misperceived or misinterpreted. In the following, we formalize these concepts with three assumptions.
Assumption $i$ (media and economic influences). At each one-month period of time $t$, insider agents are influenced by media at a probability rate $p$ and remain influenced for a period $\tau$. We assume that this influence transforms insiders into RW populist supporters. Although media can affect insiders in both directions, we focus on the growth rate and disregard negative values of $p$. The effect of the media is global, and hearing that immigration is occurring can transform some insiders into RW populist supporters irrespective of their local situation. For example, most likely as the effect of media coverage of immigration to both the EU and the UK, during the BREXIT referendum, most UK districts with low immigration voted mainly for Leave [47]. The media, alongside a lower level of tolerance to immigration, can be an important reason why, in ex-socialist countries, the large fraction of voters oppose receiving even a low overall fraction of immigrants. The probability rate $p$ can also reflect such economic factors as unemployment. Thus we use equation [43] $p^{*}=1-\exp (-p \tau)$ to calculate the probability that a randomly chosen insider agent is being influenced by the media.

Assumption ii (local influence of outsiders). In local elections in Greece in November 2010, although the far-right Golden Dawn party received only $5.3 \%$ of the vote, in some neighborhoods of Athens with large immigrant communities the party won nearly $20 \%$ [48]. This suggests that contacts between insiders and outsiders do matter. Within our network model, we maintain a constant number of $N$ insiders and then add $I(0)$ outsiders. We then increase the number of outsiders with an inflow $J_{t}$ at each moment $t$ (representing one month). We randomly place newly arriving outsiders between insider agents both of whom initially have an average number of connections (i.e., a degree) $k$. The total number of outsiders $I(t)$ is obtained by summing the monthly $J$ values according to $I(t)=I(0)+\sum_{s=1}^{t} J_{s}$. At any given moment the fraction of outsiders will equal $f_{I}(t)=I(t) /(N+I(t))$. To account for the effect of contacts between insiders and outsiders, we assume that any insider agent $i$ with $k_{i}$ total connections turns to RW populism at a rate $p^{\prime}$ when this agent is surrounded by at least $m_{i}=f_{I}^{\prime} k_{i}$ outsiders $[43,46,49]$, where $0<f_{I}^{\prime}<1$ is a constant model parameter quantifying the toleration of insiders. This assumption merits a few additional comments.

First, the probability that randomly chosen insider agent $i$ with $k_{i}$ connections is surrounded by $m_{i}$ outsiders and therefore prone to RW populism is $p_{1}\left(k_{i}, m_{i}, f_{I}\right) \equiv \sum_{j=m_{i}}^{k_{i}} f_{I}^{j}(1-$ $\left.f_{I}\right)^{k_{i}-j}\left(\begin{array}{c}k_{i} \\ k_{i}-j\end{array}\right)$. In this formula, $f_{I}$ is the true current state of the network. However the information may be biased and cause insiders to think there are more outsiders than is actually the case. If the bias is $\Delta f_{I}$, then $p_{1}\left(k_{i}, m_{i}, f_{I}+\Delta f_{I}\right)>$ $p\left(k_{i}, m_{i}, f_{I}\right)$. This increased probability $p\left(k_{i}, m_{i}, f_{I}+\Delta f_{I}\right)$ implies that the tolerance parameter $f_{I}^{\prime}$ must decrease by amount $\Delta f_{I}^{\prime}$, which we estimate using condition $p\left(k_{i}, m_{i}-\right.$ $\left.\Delta f_{I}^{\prime} k_{i}, f_{I}\right)=p\left(k_{i}, m_{i}, f_{I}+\Delta f_{I}\right)$. An implicit assumption here is that all insider agents are equally tolerant to immigrants because the tolerance parameter $f_{I}^{\prime}$ is defined as a global network property rather than an individual agent property. 
An alternative would be to assume a distribution of tolerance levels, in which case $f_{I}^{\prime}$ would represent the mean [20].

We now expand assumption (ii) with extension (A): when the immigration inflow $J$ is below some threshold $J^{\prime}$ the society becomes more tolerant. When $J<J^{\prime}$ at a given time moment, the tolerance parameter $f_{I}^{\prime}$ increases by an amount $\Delta f_{I}^{\prime}=\delta>0$; there is a balance between immigration and immigrant integration-outsiders are successfully integrated-and insiders are able to acclimate to the changes in their society. Figure 2(b) shows that the $J^{\prime}$ value for Germany is approximately 10,000 people per month. Being able to accurately determine the maximum $J^{\prime}$ value is highly relevant to the success of globalization. According to our model, immigration and integration can be the inevitable consequences of globalization when $J<J^{\prime}$. If this is not the case, globalization will be threatened by the rise of RW populism, the democratic system will enter an intolerant mode, and cooperation between nations will be downgraded on the list of political priorities.

Empirical evidence suggests that we add an opposite extension (B): as the inflow of outsiders $J$ crosses some threshold $J^{\prime \prime}$ (which does not need to be equal to $J^{\prime}$ ) society becomes less tolerant. Mathematically, extension (B) indicates that when $J>J^{\prime \prime}$, the tolerance parameter $f_{I}^{\prime}$ decreases by

$$
\Delta f_{I}^{\prime}=-\gamma J .
$$

Using the econometric models in (1), we decrease the tolerance parameter proportional to inflow $J$, where $\gamma$ is a proportionality coefficient expressing the sensitivity of insiders to high levels of outsider inflow. Figure 3(b) shows threshold $J^{\prime \prime}$ in terms of total population; that is, $J^{\prime \prime}=\alpha N$, where $\alpha$ is another proportionality coefficient. Figure 3(b) estimates the $\alpha$ value when all of the EU countries are hit by the migrant crisis. The dashed line is annual inflow below which countries have a mixed response to immigration and above which support for RW populism increases. Because $\alpha=J^{\prime \prime} / N$ and, using Figure $3(\mathrm{~b}), 12 J^{\prime \prime} / N \approx 0.004$, we obtain

$$
\alpha \approx 0.00033 \text {. }
$$

Extensions (A) and (B) are opposite limiting cases, one in which immigration is slow and the other in which immigration is rapid. Apart from the empirical evidence that these extensions are needed, brain science, for example, offers a physiological interpretation: political attitudes have a counterpart in brain structure [50-52]. If outsiders increase at a rate and in a manner perceived as controllable by insiders, the prefrontal cortex of the human brain responsible for decision making and for moderating social behavior acclimates to the new circumstances, but if the insiders perceive the outsiders to be invaders, the prefrontal cortex is supplanted by the amygdala, which induces a fighting reaction, and tolerance is suppressed.

Although with assumptions (i) and (ii) our model accounts for the processes that affect individual insider opinion, the expansion of RW populism can become extremely rapid when insiders are influenced by their peers. This welldocumented phenomenon in human interactions is further accelerated when social media is added. Thus the spread of RW populism can be highly nonlinear, much like the spread of a highly contagious disease. We include this nonlinear collective spreading mechanism in our third model assumption.

Assumption iii (mutual insider contagion). At any given moment $t$, an insider agent $i$ with $K_{i}$ connections to other insiders turns to RW populism at rate $p^{\prime \prime}$ if at time $t-1$ this agent has at least $M_{i}=K_{i} / 2 \mathrm{RW}$ populist supporters in their neighborhood. Note that, for simplicity, factor $1 / 2$ plays a role analogous to the tolerance parameter in assumption (ii). Because of connections between insider agents, when RW populism emerges anywhere in the network the populist movement is able to spread like a contagion. This collective spreading indicates that insider agents can become RW populist supporters even when there are no outsiders in the immediate neighborhood. Thus some EU countries with almost no immigration are opposed to accepting even a small group of immigrants. This may have affected the outcome of the recent US presidential election in which the winning candidate was often ridiculed in the mainstream media-an attitude represented in our model by assumption (i).

The model here assumes imitative interactions, without testing the validity of such an assumption. However, this assumption could be tested by the method of Agliari et al. [53] if the required data were available. The authors use the tools from statistical mechanics to determine from data the nature of interactions in social customs such as local and mixed marriages in Italy and neighboring European countries. The fraction of actual marriages satisfying a given condition scales differently with the fraction of all possible couples that satisfy the same condition depending on the nature of interactions between agents. If the interactions are independent (onebody model), the scaling is linear, whereas if the interactions are imitative (two-body model), the scaling is square-rooted.

We now turn to the simulation results and their implication. Figure 4 shows how in a network of 5000 agents the fraction of RW populist supporters increases when there is a constant inflow of outsiders; here $J=2$ per month. This inflow is annually approximately $0.5 \%$ of the total population, which is slightly more than the threshold value implied in Figure 3(b). Simulations with $J=2$ per month are designed to emulate the rapid limit in extension (B) described above. After approximately 37 years of rapid globalization, the network reaches a tipping point and abruptly shifts to a mode dominated by RW populism. RW populism dominates when more than $50 \%$ of the network is made up of RW populist supporters (i.e., $P>0.5$, where $P$ denotes the fraction of RW populists). The threshold is $50 \%$ because in a democracy the majority rules.

Figure 4 also shows how the simulated network under assumptions (i)-(iii) responds to shocks (red curve). At this stage, extension (B) does not yet operate. The constant annual inflow of outsiders, $J=2$, is supplemented by two events at times $t_{1}$ and $t_{2}$, when $J=200$. The state of the network, characterized by the proportion of RW populists $(P)$, exhibits a much stronger response at $t_{2}$ than at $t_{1}$, although the shock inflow $(J=200)$ is the same. This occurs because at $t_{2}$ the 


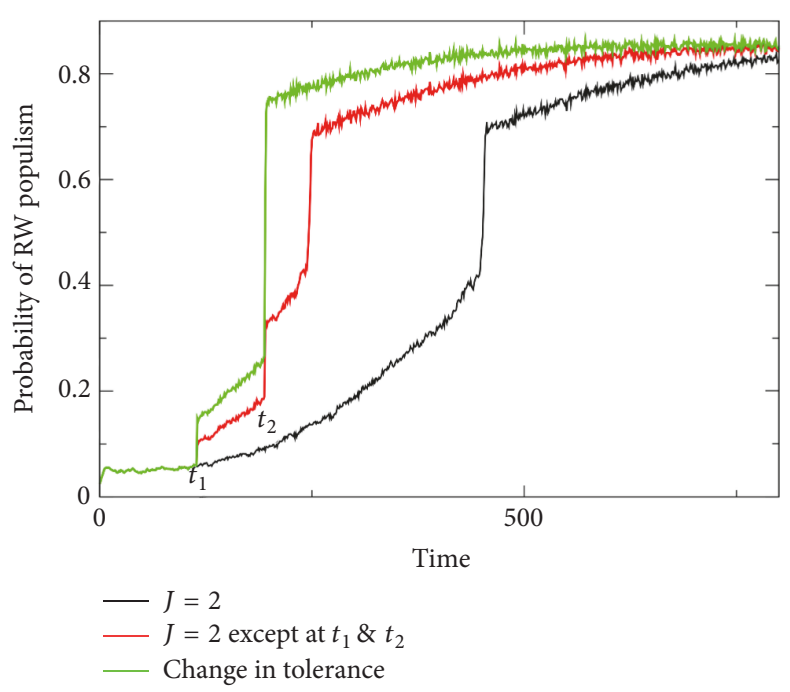

FIGURE 4: Nonlinearity, a tipping point, and the rise of right-wing populism. Using a network of $N=5,000$ agents, each with an average of 15 connections, we examine the effect of a constant inflow of outsiders at rate $J=2$ at each time step. In this setup, the total number of outsiders at any moment in time is $I(t)=$ $\sum_{i} J_{i}=\langle J\rangle$. As the fraction of outsiders, $f_{I}=I /(N+I)$, approaches the tolerance parameter, $f_{I}^{\prime}=0.15$, the presence of a tipping point causes the fraction of RW populist supporters to start increasing nonlinearly and eventually undergo a sudden jump (i.e., a discontinuous change) at about 37 years (450 months) into the simulation (black curve). The sudden jump happens much earlier if the inflow of outsiders experiences shocks at times $t_{1}$ and $t_{2}$ at which $J=200$ outsiders enter the network. In particular, as the network approaches the tipping point, the effect of exactly the same shock becomes disproportionately higher (red curve). In this case, however, the tolerance parameter is still kept constant. Finally, we also examine the case in which shocks at times $t_{1}$ and $t_{2}$ affect the tolerance parameter, where responsiveness is controlled by parameter $\gamma=0.0001$. Here, the second shock at $t_{2}$ is sufficient to instantly tip the network into RW populism (green curve). Other parameters are $p=0.007, \tau=15, p^{\prime}=0.5, p^{\prime \prime}=0.5$, and $\alpha=0.001$.

system is closer to the tipping point and consequently more unstable than at $t_{1}$. Because in real-world data the value of $J$ can be biased due to estimation errors or misinterpreted information, our results suggest that approaching the tipping point can be concurrent with strong nonlinear effects such that even a small shock can trigger a transition to a mode dominated by RW populism. This can be even more explosive (in terms of $P$ ) if extension (B) is allowed to operate, that is, if the tolerance parameter $f_{I}^{\prime}$ changes with $J$.

Figure 4 shows a third simulation (green curve) in which the dynamics operate under assumptions (i)-(iii) with extension (B). The tolerance parameter $f_{I}$ thus changes with $J$ as prescribed by (2). Because of the decreasing tolerance, the second shock at $t_{2}$ can now push the system beyond the tipping point, and thus the dominance of RW populism occurs earlier than in the two previous simulations.

From the simulations in Figure 4 alone, it is unclear how much the local influence of outsiders (assumption (ii)) contributes to the rise of RW populism relative to the insider

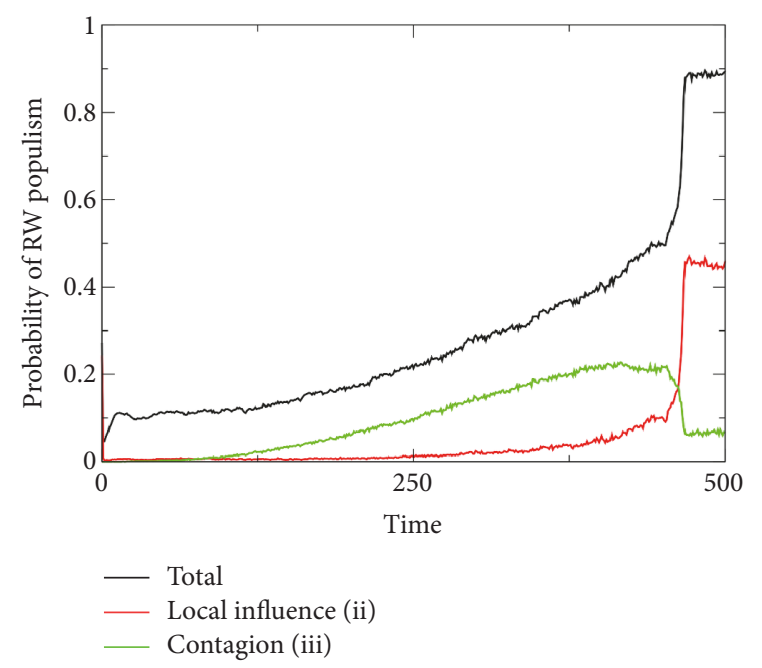

FIGURE 5: Breakdown of the causes of right-wing populism. Figure 4 shows that the probability of RW populism, $P$, suddenly increases as society approaches a tipping point but remains silent on the underlying causes. Here we discern between the contributions of local outsider influence (assumption (ii)) and mutual insider contagion (assumption (iii)). Far from the tipping point, $P$ mainly responds to local outsider influence (ii). By contrast, as the network approaches its tipping point, mutual insider contagion (iii) takes over and accelerates the transition to RW populist dominance. Parameter values are $N=5,000$ with an average degree of $15, J=2$, $p=0.007, \tau=15, p^{\prime}=0.7$, and $p^{\prime \prime}=0.8$.

contagion (assumption (iii)). Figure 5 shows these contributions. After the initial transients fade, the local influence of outsiders drives the increase in RW populists in the network. The contribution of mutual insider contagion is relatively small until the system approaches a tipping point. Near the tipping point, contagion spreads rapidly and overtakes the local outsider influence as the main contributor to the rise of RW populism. Thereafter the RW populist movement can sustain itself without support from the outside.

In the regime of moderate immigration inflows $\left(J^{\prime}<J<\right.$ $\left.J^{\prime \prime}\right)$, we can examine the dynamics of our complex network using the mean-field theory (MFT) analytic technique. When the number of agent connections does not deviate greatly from the network average, the probability $P$ that a randomly chosen insider agent $i$ is an RW populist supporter due to any of the processes underlying assumptions (i)-(iii) is

$$
\begin{aligned}
P= & p^{*}+p^{\prime} p_{1}\left(k_{i}, m_{i}, f_{I}\right)+p^{\prime \prime} p_{1}\left(K_{i}, M_{i}, P\right) \\
& -p^{*} p^{\prime} p_{1}\left(k_{i}, m_{i}, f_{I}\right)-p^{*} p^{\prime \prime} p_{1}\left(K_{i}, M_{i}, P\right) \\
& -p^{\prime} p_{1}\left(k_{i}, m_{i}, f_{I}\right) p^{\prime \prime} p_{1}\left(K_{i}, M_{i}, P\right)
\end{aligned}
$$

where the last three terms avoid double counting in accordance with the probability theory formula $P(A \cup B \cup C)=$ $P(A)+P(B)+P(C)-P(A) P(B)-P(A) P(C)-P(B) P(C)$ for three mutually independent events $A, B$, and $C$ that cannot occur simultaneously. In the MFT approximation, we can drop index $i$ because no single agent is markedly different from the collective average. Previously we set $M=K / 2$ 


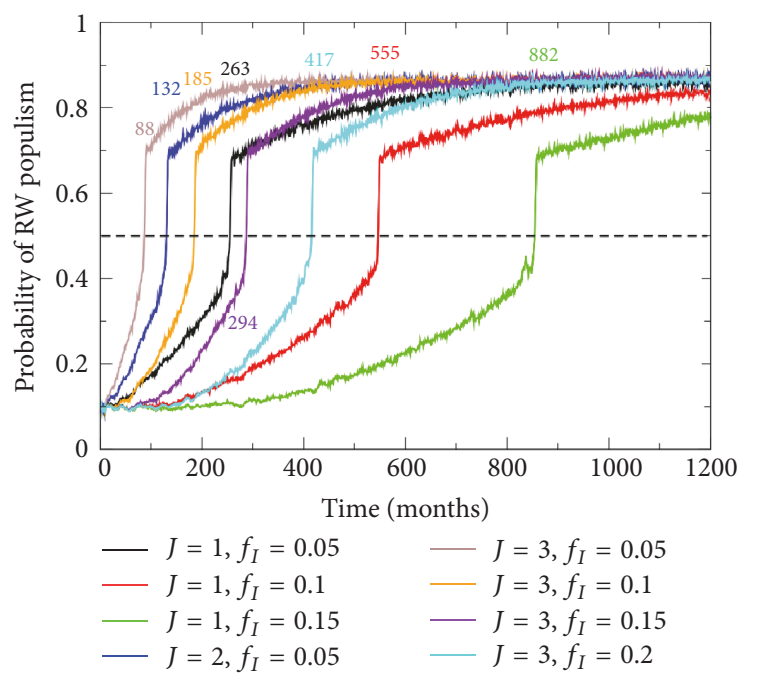

FIgUre 6: Predicting the timing of $R W$ populism. We find that for a broad range of outsider inflows $(J)$ and tolerance parameter values $\left(f_{I}^{\prime}\right),(5)$ predicts the moment at which $P>0.5$ in a manner that agrees favorably with the simulation results. Except for $\gamma=0$, other parameters are the same as in Figure 4.

for simplicity, but the peer pressure measured by the value of the proportionality factor between $M$ and $K$ can differ between countries or regions. In addition, parameters $p^{\prime}$ and $p^{\prime \prime}$ are constants only in theory. The real social dynamics are such that these parameters may change in response to rumors, political manipulations, or outside shocks. If parameters $p^{\prime}$ and $p^{\prime \prime}$ substantially increase, the value of $P$ also increases, thus further improving the prospects for RW populism dominance. In our framework, due to democracy's majority rule principle, when $P$ approaches 0.5 the nonlinear processes embedded in assumptions (ii) and (iii) cause a sudden transition to RW populist mode.

Because a theoretical model is more useful if it has predictive power $[54,55]$, we show how a network of agents under assumptions (i)-(iii) leads to a simple formula for the timing at which RW populism starts to dominate,

$$
t_{t h}=\frac{N f_{I}^{\prime}}{J\left(1-f_{I}^{\prime}\right)}-\frac{I(0)}{J} .
$$

Gaining this result involves three steps. First, if the immigration inflow is constant, then the number of outsiders in the network after $t$ time steps is $I(0)+J t$. Second, the total population size thus equals $N+I(0)+J t$. Finally, (5) follows if the current fraction of outsiders $(I(0)+J t) /(N+$ $I(0)+J t)$ is equated with the critical parameter $f_{I}^{\prime}$. Figure 6 shows that, for a number of immigration inflow-tolerance parameter pairs $\left(J, f_{I}^{\prime}\right)$, the simulated timing of the shift to RW populist mode (i.e., $P>0.5$ ) fits theoretical predictions. In conjunction with the empirical data on tolerance towards immigrants in the EU countries, the formula in (5) could be used to provide an estimate of when a given country might be approaching a possible tipping point to RW populism dominance.
Numerical simulations allow us to examine not only isolated single networks, but also the interdependence between two or more networks. Note that there is a potential for a cascade effect when an RW populist movement in one network causes the rise of RW populist movements in other networks. This cascade effect is growing in relevance because expanding globalization is causing countries to become increasingly similar to each another, and this similarity increases in such supranational organizations as the EU in which borders between nation states are rapidly fading.

To examine how interdependence affects the rise of RW populism, we set up two random, economically equivalent ER networks (equal $p$ in the model) with different tolerance levels towards outsiders (different $f_{I}^{\prime}$ in the model). To the usual intraconnections within each network we add interconnecting agents that link with their counterparts in the other network. Apart from this addition, we retain the same model assumptions as previously held.

To examine the effects of interconnectedness, we first run numerical simulations of two independent networks without interconnections [see Figure 7(a)]. As expected, when the inflow level of outsiders is the same $(J=2)$ the network with a higher tolerance parameter $\left(f_{I, 1}^{\prime}=0.4\right)$ reaches the tipping point much later than the network with a lower tolerance parameter $\left(f_{I, 2}^{\prime}=0.2\right)$. When the networks are interconnected and the more tolerant network experiences an increased inflow $\left(J_{2}=4\right)$ and a shock $(J=500)$ at time $t_{1}=500$ its susceptibility to RW populism increases and it also affects the other network and shortens the time of transition to RW populism [see Figure 7(b)]. It would appear that countries do not want to be the first to cross the line, but in an interconnected world being second is easier.

\section{Discussion and Conclusion}

Why some countries (e.g., the ex-socialist EU countries) strongly oppose receiving immigrants while others (e.g., the USA) have a long history of receiving immigrants is an important topic in the social sciences and, more recently, a major issue for the EU. Perhaps receiving immigrants has been an ongoing pattern in the USA because there is no single dominant ethnicity and thus a clear distinction is made between USA national identity and the country of origin of its citizens. In addition, because USA citizens are people from all over the world, there is no single dominant religious, ethnic, or cultural group that can organize and threaten the established social order. In France we find the opposite. There is a large group of immigrants with different language and religion from the French majority, whose presence can instill fear among the majority. Fear exacerbated by an inflow rate of immigrants that exceeds the rate of their integration can lead to a volatile situation, one that is often resolved in one of two ways. Either there is an immigrant uprising as exemplified by the Visigoth immigrants and their ex-Roman commander Alaric who plundered Rome in 410 or the majority population suppresses the inflow of immigrants. Currently this second option is often accomplished by supporting populist rightwing parties. 


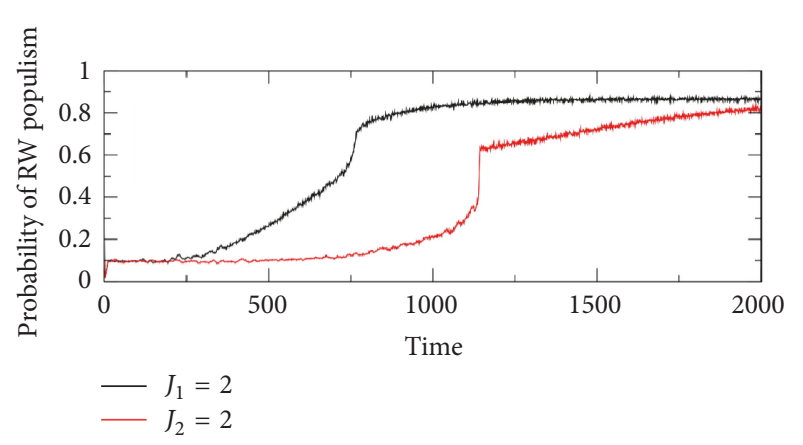

(a)

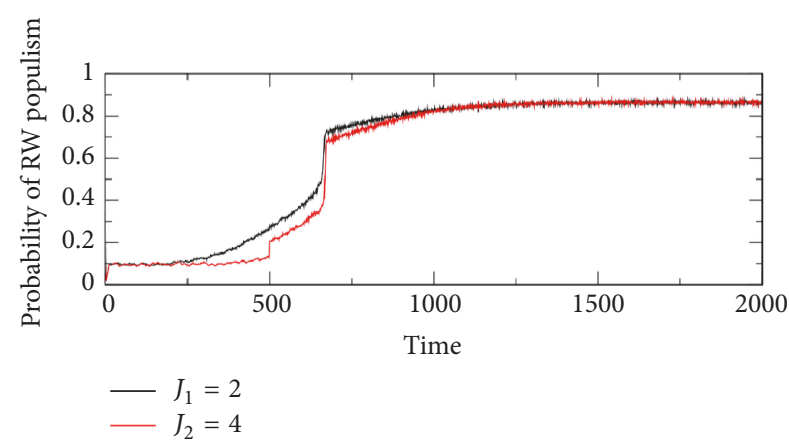

(b)

Figure 7: Interconnected networks or why "somebody else's problem" easily turns into "my problem." In (a) we show the case when there are no interlinks between networks. The tolerance parameters between the two networks differ, $f_{I, 1}=0.2$ and $f_{I, 1}=0.4$, while the inflows into both networks are the same, $J_{1}=J_{2}=2$. (b) More tolerant network is now exposed to a higher inflow, $J_{2}=4$, and a shock at $t_{1}=500$. The average number of connections for intraconnections (interconnections) in both networks equals 15 (10). The other parameters are the same as in Figure 4.

Although globalization was conceived to allow capital and labor to move freely across national borders, real-world globalization is affected by a multitude of noneconomic factors such as ethnicity, culture, and religion. With so many factors at play, globalization is an enormously complex process and often noneconomic factors do not align with purely economic factors. This misalignment can lead to frustrations that feed populist movements. By opposing the collaboration that comes with globalization, populist movements act as a feedback mechanism that pushes the general population towards becoming more ideologically rigid, and this, in turn, further accelerates the populism [56]. A strengthened populist movement can also trigger tectonic shifts in world affairs as exemplified by BREXIT in the UK and the recent 2016 US presidential election.

Problems in a globalized world rarely confine themselves to one place. Interdependence makes the developed countries more alike and synchronizes their social dynamics. This synchronization can cause political shifts in one country to spill over into other countries, and this is what enables the rise of RW populism to spread across large regions of the world. After BREXIT and the 2016 US presidential election, political elites should not expect to continue business as usual. Being the first to adopt a major political shift with a high probability of negative economic consequences is difficult, but once that line has been crossed the interdependence of globalization makes cascades (domino effects) an active possibility. No one wants to be first, but many are ready to be second.

The tipping point that brings on the rise of RW populism may be reached more quickly when voters face a binary choice, for example, the "yes" or "no" choice in the UK BREXIT referendum and the two major-party candidates in the recent US presidential election. In both cases the populist option secured a narrow victory. As mentioned above, the polls indicate that the populist party in Austria can expect to receive $34 \%$ of the votes, but the populist party candidate in the presidential race can expect close to $51 \%$. A simple way to understand these percentages is to assume that political attitudes of voters are approximately symmetrical in their distribution across the political spectrum from left to right. Consequently, if leftist voters comprise $\psi_{L} \%$ of the total population, then RW populist voters will maintain a similar presence; that is, $\psi_{R} \% \approx \psi_{L} \%$. Facing this binary choice, the centrist voters have no one representing their views and thus are likely to vote evenly between the two available options. An implication is that when $\psi_{L} \% \approx \psi_{R} \% \approx 33 \%$, even a slight (statistically significant) imbalance in favor of $\psi_{R} \%$ over $\psi_{L} \%$ can tip the society towards RW populism. In Austria $\psi_{R} \% \approx 36 \%$ seems to be sufficient to make the RW populist candidate a front runner in the presidential race.

The final outcome of the battle between the conflicting factors surrounding globalization will almost surely have tremendous economic implications. If a country approaches its tipping point, how will the ensuing volatility affect its long-term credit rating? If a domino effect cascades across a large region of the EU or the entire EU, how will that affect the Euro and the common banking system? Without a proper resolution of the migrant crisis, what will be the impact on systemic risk? In an attempt to shed light on some of the factors and underlying processes that affect the success of globalization, we offer an empirically backed theoretical model of the rise of RW populism in response to unsustainable immigration inflows.

Our model emphasizes the need for controlled globalization in which immigration inflows into a society are balanced with the ability of the society to integrate the immigrants. This ability is arguably improved when immigrants mix with the native population, which is a principle practiced in Singapore where immigrant hubs are discouraged, and tenants in government-built housing (comprising $88 \%$ of all housing) must be of mixed ethnic origin [20]. Because tolerance towards immigrants is conditional, when immigration inflows overshadow integration rates the society can be tipped into RW populism, an intolerant mode of functioning. The rise of RW populism can occur because elections are by their nature stochastic, and they resemble a mathematical random walker. Left to its own devices, a random walker will eventually hit an absorbing barrier. Here this barrier, 
of course, is a metaphor for the demise of globalization, ironically at the very hands of the progressive system (i.e., democracy) that made globalization possible in the first place.

\section{Disclosure}

A version of this work was presented in Warsaw at "Econophysics Colloquium 2017."

\section{Conflicts of Interest}

The authors declare that they have no conflicts of interest.

\section{Acknowledgments}

The authors are grateful to S. Galam and T. Lipic for helpful suggestions. Boris Podobnik received the support from Slovenian Research Agency (ARRS) via Project J5-8236 and from the University of Rijeka. Boris Podobnik and H. E. Stanley received support from the Defense Threat Reduction Agency (DTRA), the Office of Naval Research (ONR), and the National Science Foundation (NSF) (Grant CMMI 1125290). Marko Jusup was supported by the Japan Science and Technology Agency (JST) Program to Disseminate Tenure Tracking System.

\section{References}

[1] H. Grubel and A. Scott, "The international flow of human capital," American Economic Review, vol. 56, pp. 268-274, 1966.

[2] G. C. Hufbauer and K. Suominen, Globalization at Risk: Challenges to Finance and Trade, Yale University Press, 2010.

[3] F. Docquier and H. Rapoport, "Globalization, Brain Drain, and Development," Journal of Economic Literature, vol. 50, pp. 681730, 2012

[4] D. Rodrik, The Globalization Paradox: Democracy and the Future of the World Economy, W. W. Norton \& Company, New York, USA, 2011.

[5] B. R. Chiswick, "The Effect of Americanization on the Earnings of Foreign-born Men," Journal of Political Economy, vol. 86, no. 5, pp. 897-921, 1978.

[6] G. J. Borjas, Heaven's Door: Immigration Policy and the American Economy, Princeton University Press, 1999.

[7] G. J. Borjas, “The economics of immigration," Journal of Economic Literature, vol. 32, pp. 1667-1717, 1994.

[8] G. J. Borjas, "Assimilation, Changes in Cohort Quality, and the Earnings of Immigrants," Journal of Labor Economics, vol. 3, no. 4, pp. 463-489, 1985.

[9] D. Swank and H. G. Betz, "Globalization, the welfare state and right-wing populism in Western Europe," Socio-Economic Review, vol. 1, no. 2, pp. 215-245, 2003.

[10] J. Gibson and D. McKenzie, "Eight Questions about Brain Drains," Journal of Economic Perspectives, vol. 25, no. 3, pp. 107128, 2011.

[11] H. Betz, "Politics of Resentment: Right-Wing Radicalism in West Germany," Comparative Politics, vol. 23, no. 1, pp. 45-60, 1990.

[12] R. Knight, "Haider, the freedom party and the extreme right in Austria," Parliamentary Affairs, vol. 45, no. 3, pp. 285-299, 1992.
[13] P. Fysh and J. Wolfreys, "Le pen, the National Front and the extreme right in France," Parliamentary Affairs, vol. 45, no. 3, pp. 309-326, 1992.

[14] G. Voerman and P. Lucardie, "The extreme right in the Netherlands: The centrists and their radical rivals," European Journal of Political Research, vol. 22, no. 1, pp. 35-54, 1992.

[15] W. D. Chapin, "Explaining the electoral success of the new right: The German case," West European Politics, vol. 20, no. 2, pp. $53-$ 72, 1997.

[16] J. M. Smith, "Does crime pay? Issue ownership, political opportunity, and the populist right in Western Europe," Comparative Political Studies, vol. 43, no. 11, pp. 1471-1498, 2010.

[17] B. Bonikowski and P. DiMaggio, "Varieties of American Popular Nationalism," American Sociological Review, vol. 81, no. 5, pp. 949-980, 2016.

[18] D. Rodrik, "How far will international economic integration go?” Journal of Economic Perspectives, vol. 14, no. 1, pp. 177-186, 2000.

[19] B. Davis, "Despite his heritage, prominent economist backs immigration cut," The Wall Street Journal, 1996, https://www.hks .harvard.edu/fs/gborjas/publications/popular/WSJ042696.pdf.

[20] B. Podobnik, M. Jusup, Z. Wang, and H. E. Stanley, "How fear of future outcomes affects social dynamics," Journal of Statistical Physics, vol. 167, no. 3-4, pp. 1007-1019, 2017.

[21] R. Reuveny, "Climate change-induced migration and violent conflict," Political Geography, vol. 26, no. 6, pp. 656-673, 2007.

[22] T. C. Schelling, "Dynamic models of segregation," Journal of Mathematical Sociology, vol. 1, pp. 143-186, 1971.

[23] R. Axelrod, "The dissemination of culture: a model with local convergence and global polarization," Journal of Conflict Resolution, vol. 41, no. 2, pp. 203-226, 1997.

[24] M. McPherson, L. Smith-Lovin, and J. M. Cook, "Birds of a Feather: Homophily in Social Networks," Annual Review of Sociology, vol. 27, pp. 415-444, 2001.

[25] T. Antal, P. L. Krapivsky, and S. Redner, "Dynamics of social balance on networks," Physical Review E, vol. 72, Article ID 036121, 2005

[26] S. Marvel, J. Jon Kleinbergb, D. Robert, R. D. Kleinberg, and S. Strogatz, "Continuous-Time Model of Structural Balance," Proceedings of the National Academy of Sciences of the United States of America, vol. 108, no. 5, pp. 1771-1776, 2011.

[27] C. Gracia-Lazaro, L. M. Flora, and Y. Moreno, "Selective Advantage of Tolerant Cultural Traits in the Axelrod-Schelling Model," Physical Review E, vol. 83, Article ID 056103, 2011.

[28] F. Aguiar and A. Parravano, "Tolerating the Intolerant: Homophily, Intolerance, and Segregation in Social Balanced Networks," Journal of Conflict Resolution, vol. 59, no. 1, pp. 2950, 2015.

[29] M. Lim, R. Metzler, and Y. Bar-Yam, "Global pattern formation and ethnic/cultural violence," Science, vol. 317, no. 5844, pp. $1540-1544,2007$

[30] R. M. Dancygier, Immigration and Conflict in Europe, Studies in Comparative Politics, Cambridge University Press, 2010.

[31] R. M. Dancygier and D. D. Laitin, "Immigration into Europe: Economic Discrimination, Violence and Public Policy," Annual Review of Political Science, vol. 17, pp. 43-64, 2014.

[32] S. Galam and M. A. Javarone, "Modeling Radicalization Phenomena in Heterogeneous Populations," PLoS ONE, vol. 11, Article ID e0155407, 2016. 
[33] R. J. Sampson, S. W. Raudenbush, and F. Earls, "Neighborhoods and violent crime: a multilevel study of collective efficacy," Science, vol. 277, no. 5328, pp. 918-924, 1997.

[34] http://www.unhcr.org/.

[35] http://www.lucify.com/the-flow-towards-europe/.

[36] http://www.electograph.com/.

[37] C. Castellano, M. Marsilli, and A. Vespignani, "Nonequilibrium Phase Transition in a Model for Social Influence," Physical Review Letters, vol. 85, p. 3536, 2000.

[38] D. Card, A. Mas, and J. Rothstein, "Tipping and the Dynamics of Segragation," The Quarterly Journal of Economics, vol. 123, no. 1, pp. 177-218, 2008.

[39] https://en.wikipedia.org/wiki/List_of_non-state_terrorist_incidents.

[40] http://www.mipex.eu/what-is-mipex.

[41] H. Betz, "The New Politics of Resentment: Radical Right-Wing Populist Parties in Western Europe," Comparative Politics, vol. 25, no. 4, pp. 413-427, 1993.

[42] K. Popper, The Open Society and Its Enemies: The Spell of Plato, vol. 1, Routledge, UK, 1945.

[43] A. Majdanzic, B. Podobnik, S. V. Buldyrev, Y. Kenett, S. Havlin, and H. E. Stanley, "Spontaneous recovery in dynamical networks," Nature Physics, vol. 10, pp. 34-38, 2014.

[44] B. Podobnik, V. Vukovic, and H. E. Stanley, "Does the wage gap between private and public sectors encourage political corruption?" PLoS ONE, vol. 10, no. 10, Article ID e0141211, 2015.

[45] J.-H. Lee, M. Jusup, B. Podobnik, and Y. Iwasa, "Agent-based mapping of credit risk for sustainable microfinance," PLOS ONE, vol. 10, no. 5, Article ID e0126447, 2015.

[46] D. J. Watts, "A simple model of global cascades on random networks," Proceedings of the National Academy of Sciences of the United States of America, vol. 99, no. 9, pp. 5766-5771, 2002.

[47] http://theconversation.com/hard-evidence-how-areas-withlow-immigration-voted-mainly-for-brexit-62138.

[48] http://www.dw.com/en/golden-dawn-trial-begins-in-greece/a18393111.

[49] B. Podobnik, D. Horvatic, T. Lipic, M. Perc, J. M. Buldu, and H. E. Stanley, "The Cost of Attack in Competing Networks," Journal of The Royal Society Interface, vol. 12, Article ID 20150770, 2015.

[50] R. Kanai, T. Feilden, C. Firth, and G. Rees, "Political Orientations Are Correlated with Brain Structure in Young Adults," Current Biology, vol. 21, no. 8, pp. 677-680, 2011.

[51] G. Zamboni, M. Gozzi, F. Krueger, J.-R. Duhamel, A. Sirigu, and J. Grafman, "Individualism, conservatism, and radicalism as criteria for processing political beliefs: a parametric fMRI study," Social Neuroscience, vol. 4, no. 5, pp. 367-383, 2009.

[52] D. R. Oxley, K. B. Smith, J. R. Alford et al., "Political attitudes vary with physiological traits," Science, vol. 321, no. 5896, pp. 1667-1670, 2008.

[53] E. Agliari, A. Barra, A. Galluzzi, M. A. Javarone, A. Pizzoferrato, and D. Tantari, "Emerging heterogeneities in Italian customs and comparison with nearby countries," PLoS ONE, vol. 10, no. 12, Article ID e0144643, 2015.

[54] S. Galam, "The Trump phenomenon: an explanation from sociophysics," International Journal of Modern Physics B, vol. 31, no. 10, 17 pages, 2017.

[55] R. Kennedy, S. Wojcik, and D. Lazer, "Improving election prediction internationally," Science, vol. 355, no. 6324, pp. 515520, 2017.

[56] M. Jusup, T. Matsuo, and Y. Iwasa, "Barriers to Cooperation Aid Ideological Rigidity and Threaten Societal Collapse," PLoS Computational Biology, vol. 10, no. 5, Article ID e1003618, 2014. 


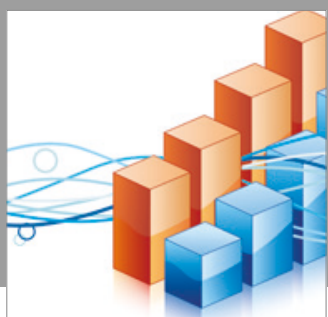

Advances in

Operations Research

vatersals

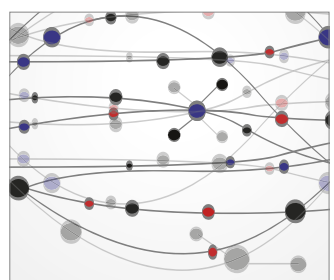

\section{The Scientific} World Journal
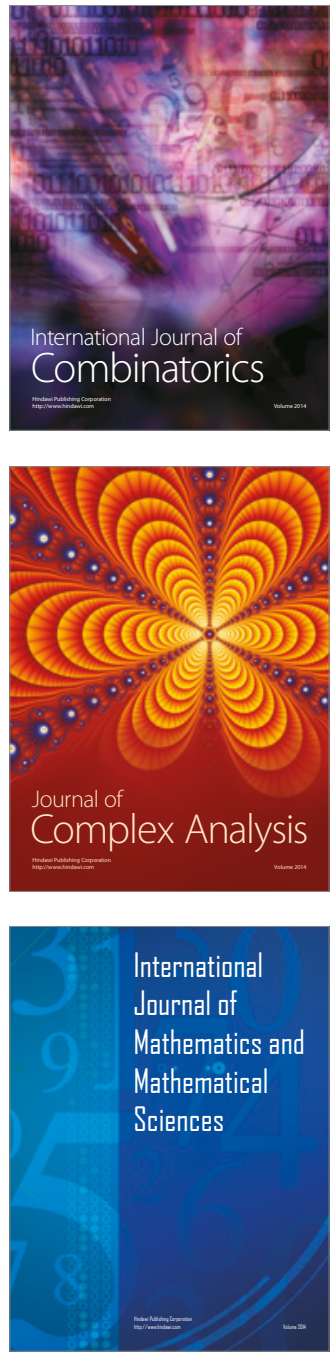
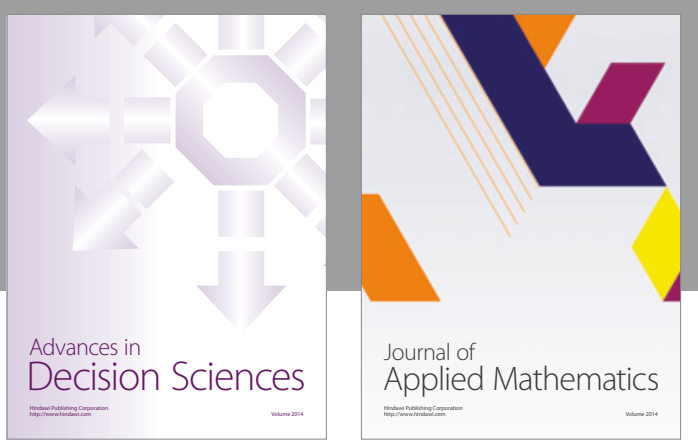

Algebra

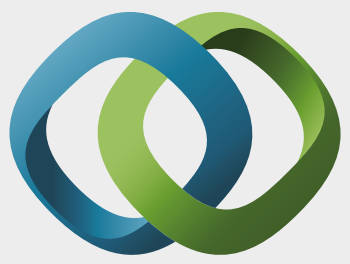

\section{Hindawi}

Submit your manuscripts at

https://www.hindawi.com
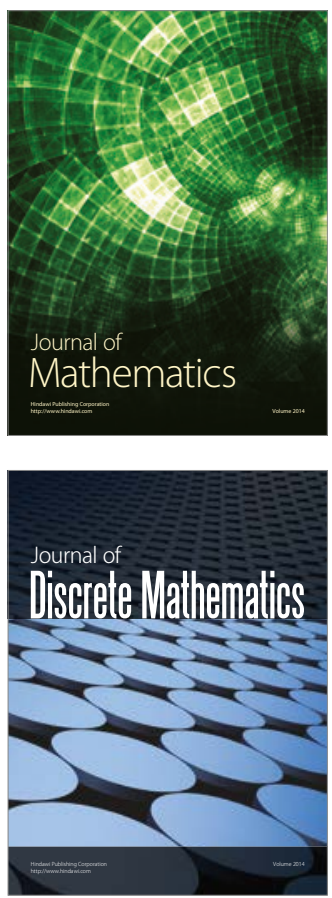

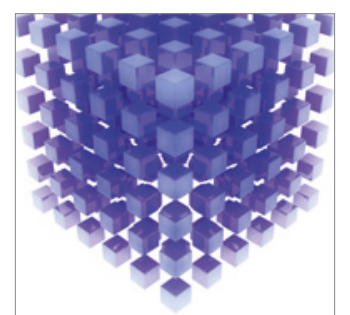

Mathematical Problems in Engineering
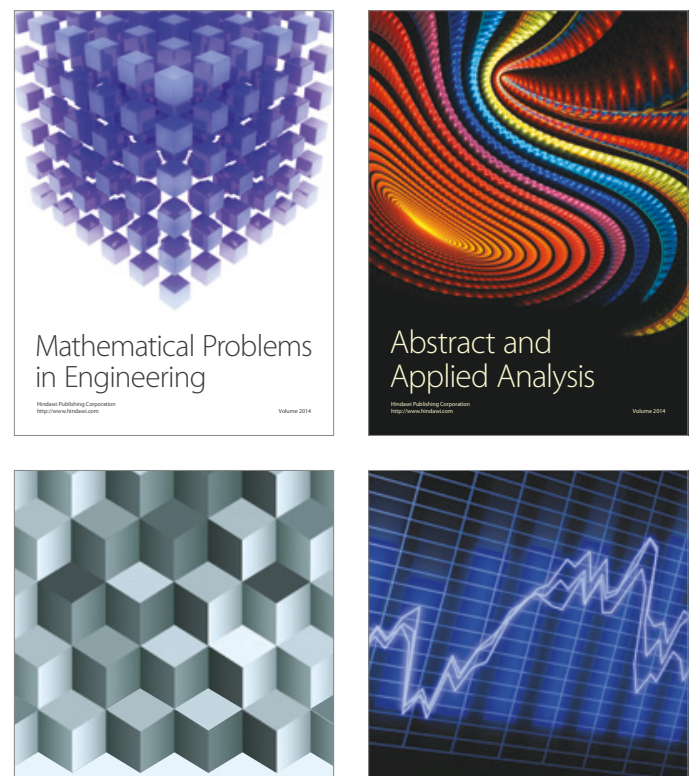

Journal of

Function Spaces

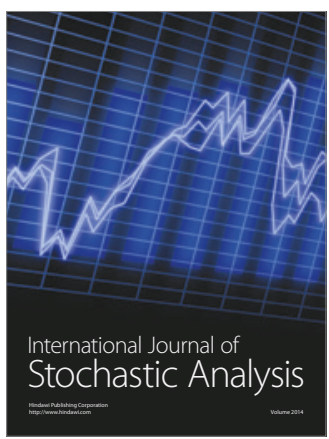

Probability and Statistics
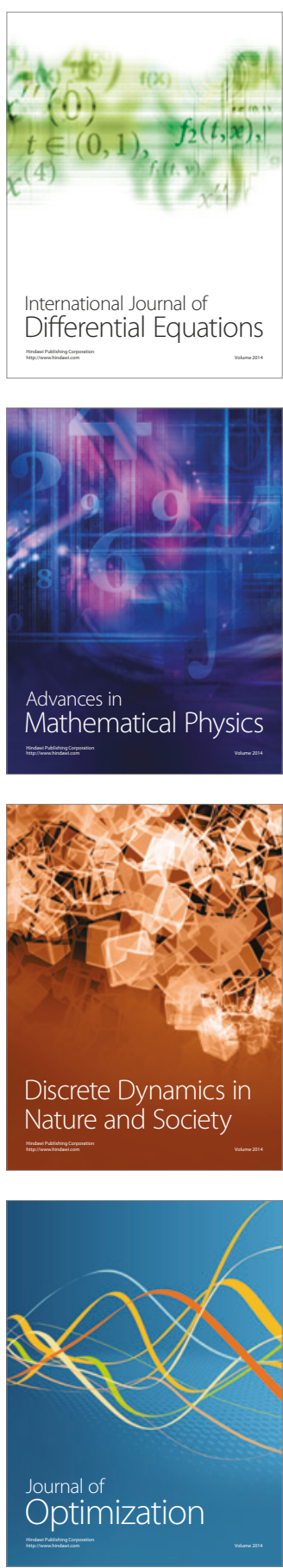